\title{
Research on the Construction of Advanced Metering Infrastructure for Typical Community
}

\author{
Li Ting ${ }^{1}$, Zhang Shiyu ${ }^{2}$, Kong Xiangyu ${ }^{2}$
}

1. Department of electrical engineering, Guang Xi Technological College of Machinery and Electricity 2. Key Laboratory of Smart Grid of Ministry of Education, Tianjin University, Tianjin 300072, China

\section{Keywords. Advanced Metering Infrastructure; Power Fiber to the Home; Broadband Power Line Carrier}

Abstract.In order to construct and promote the intelligent grid demonstration community project, this paper presents two typical modes of networking for Advanced Metering Infrastructure (AMI). Firstly, two typical communities are analyzed. Secondly, two typical modes of networking are studied and compared. At last, how to combine the two modes with typical community is discussed. This analytical results provides the theoretical reference for the construction and promotion of the intelligent grid demonstration community project in Guangxi province and even around China.

\section{INTRODUCTION}

The electric grids are suffering a modernization process in the area of generation, transmission, distribution and use of electricity. This modernization is being driven by smart grid, and one of the initiatives fields of the smart grid is Advanced Metering Infrastructure (AMI) [1]. Due to the development of communication technology and information technology in recent years, AMI is improved rapidly, and now it becomes more attractive [2].

AMI is the integrated system that contains the hardware and software, which could transmit the electricity consuming information and the consuming behavior information based on the communication network, so it is the fundamental mould of the smart gird [3-4]. Literature [5] analyzes AMI related communication technologies and proposes a typical structure of China AMI, but it doesn't describe the communication framework of local area and home area. Literature [6] focuses on the problem of fostering the large scale deployment of EV in smart grids using the AMI technologies, but it doesn't refer to the commnunication architecture. Literature [7] presents the robust communication architecture for the current distribution system, but it ignores the electricity consuming behaviors in the home area network.

In this paper two typical communities and two typical modes of networking of AMI are presented. After analyzing the features of modes and communities, the applicable mode for different communities is given.

\section{SURVEY AND RESEARCH OF TYPICAL COMMUNITY}

\section{A. Local Area Network Technologies}

Different communication networks could be applied with various communication technologies, here we analyze and compare these communication technologies separately according to the communication network layers. A. Local Area Network Technologies The technologies that could be used in the local area network are as follows, electric power optical fiber, Broadband Power Line Carrier (BPLC), wireless private network (230MHz), wireless Multi-hop network and GPRS / CDMA wireless public network. The construction cost, transmission rate and reliability of all these technologies as listed in table I. Considering the features of these technologies in table I, the electric power optical fiber is the priority in local area network. 
TABLE I. LOCAL AREA NETWORK TECHNOLOGIES

\begin{tabular}{|c|c|c|c|}
\hline Technology & Construction & Transmission & Reliability \\
\hline electric power & High & Very high & Very high \\
\hline BPLC & Low & Normal & High \\
\hline $\begin{array}{c}\text { wireless private } \\
(230 \mathrm{MHz})\end{array}$ & Low & Low & Low \\
\hline $\begin{array}{c}\text { wireless Multi-hop } \\
\text { GPRS/CDMA }\end{array}$ & Low & Low & Low \\
\hline
\end{tabular}

\section{B. Home Area Network Technologies}

The technologies that could be used in the home area network are as follow, Broadband Power Line Carrier (BPLC), RS485 bus, Wireless Fidelity (WiFi) and ZigBee. The construction cost, transmission rate and reliability of all these technologies as listed in table II.

\section{TABLE II. LOCAL AREA NETWORK TECHNOLOGIES}

\begin{tabular}{|c|c|c|c|}
\hline Technology & Construction & Transmission & Reliability \\
\hline BPLC & Low & $>512 \mathrm{kbps}$ & High \\
\hline RS 485 & Low & $1200-9600 \mathrm{bps}$ & High \\
\hline WiFi & Low & Near $300 \mathrm{Mbps}$ & High \\
\hline ZigBee & Low & $70 \mathrm{kbps}-$ & High \\
\hline
\end{tabular}

Considering the features of these technologies in table II, the WiFi is the preferential technology that could be used in home area network.

\section{Two Typical Modes of Network in Advanced Metering Infrastructure}

In this part, two current typical residential community are selected to survey and research, including environment, the number of users, the distance from substation to the $10 \mathrm{kV}$ distribution transformer and the existing network and so on.

The basic situation of the research community is shown in Table III.

\section{TABLE III THE BASIC SITUATION OF THE RESEARCH COMMUNITY}

\begin{tabular}{|c|c|c|}
\hline Community & Number of users & Survey results \\
\hline A & 2435 & $\begin{array}{c}\text { High occupancy rate, network } \\
\text { equipments are installed, the } \\
\text { distance from substation to the } \\
10 \mathrm{kV} \text { distribution transformer is } \\
200 \mathrm{~m} .\end{array}$ \\
\hline B & 5249 & $\begin{array}{c}\text { The new community, meters and } \\
\text { network equipments are not } \\
\text { installed, the distance from } \\
\text { substation to the } 10 \mathrm{kV} \\
\text { distribution transformer is } 4 \mathrm{~km} .\end{array}$ \\
\hline
\end{tabular}

In this part, two mature networking programs, power fiber to the home (PFTTH) and broadband power line carrier (BPLC), are discussed from building the electricity consumption data collection and intelligent electricity consumption service system. 


\section{THE COMMUNICATION BANDWIDTH NEEDED}

Smart electricity information collection could be used for collecting the user's electricity information real time or periodically. The electricity information includes: the current remaining amount, the current active power, the current electricity price and the current total consumed active power.

According to the character of the display screen of the smart meters, assumed that each of above four electricity information is 6-bit integer and 2-bit decimal places, as a result, all these information need 27 bits. Assuming the transmission time is 1 second for each bit data, then the required bandwidth for the electricity information transmission is $108 \mathrm{bps}$.

Smart electricity consuming behaviors include the following operations: (1) Exchanging information with 95598 website, and acquiring the electricity consuming information and electricity consuming strategy; (2) Monitoring the condition of electrical equipments; (3) Controlling the state of electrical equipments. Because the electricity consuming information and electricity consuming strategy are downloaded from the 95598 website, its transmission allows delay in some extent.

The electricity consuming behavior controlling information is interacted between the smart interactive terminals and the intelligent socket or the intelligent appliances, and users can monitor and control the intelligent electric equipments' state based on the home area network. For the controlling command is very short, its required bandwidth is about $20 \mathrm{kbps}$.

\section{The CONSTRUCTION PROGRAM OF PFTTH}

The construction range of PFTTH program is from $10 \mathrm{kV}$ distribution transformers to the communication network of user's home. PFTTH network is based on fiber composite low-voltage cables and passive optical network (xPON) fiber-optic networking technology. xPON is a singlemultipoint structure of single-fiber bidirectional optical accessing network, including optical line terminal (OLT), optical distribution network (ODN) of the network side and optical network unit (ONU) of the user-side [8-9].

D. The electricity consumption data collection based on PFTTH

The network program of electricity consumption data collection based on PFTTH is shown in Figure 1.

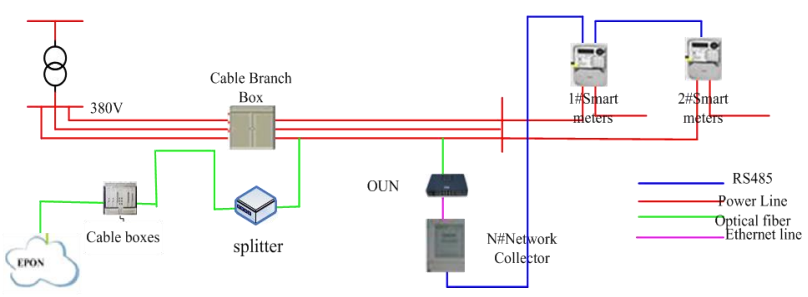

Fig.1 The network program of electricity consumption data collection based on PFTTH

The installation location of related equipment is as follows: OLT is installed in cable transfer box, used to connect fiber optic trunk and splitter. Next to the meter box in corridor another a small device box is set to place the ONU, power outlet, splice boxes and other equipments, ONU's power is taken from the meter box total gate. Network logger is installed in the corridor, the power is taken from the meter box and the total gate with separate control switch.

\section{E. The intelligent electricity consumption service system based on PFTTH}

The construction of intelligent electricity consumption service system, takes the corridor as a unit, through client/server to achieve the communication with broadcasting, telecom and other operators 
of the system. The optical channel is extended to each corridor's splitter, through the optical fiber composite low-voltage cable, then extended to the home through the optical fiber composite lowvoltage cable channel, using covered wire cable connect with optical fiber composite low-voltage cable accessing ONU to achieve the access to the home gateway. Figure 2 shows the logic of intelligent electricity consumption based on PFTTH

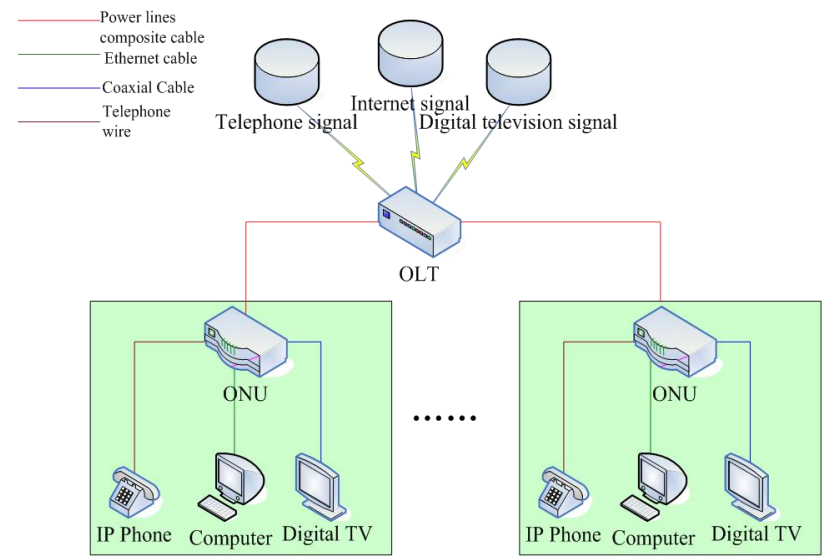

Fig.2 The logic of intelligent electricity consumption service system based on PFTTH

Fig. 3 shows the networking solutions of intelligent electricity consumption service system based on PFTTH.

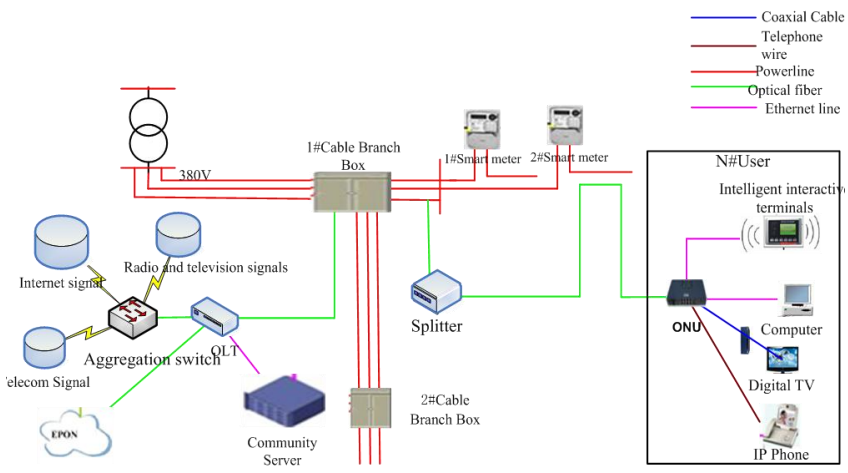

Fig.3 The networking solutions of intelligent electricity consumption service system based on PFTTH

There are several options for network communication within the user households, besides Ethernet lines and coaxial cable, etc. noted in Figure 3, can be power line carrier communication, can also be wireless communications such as ZigBee and WiFi.

\section{THE CONSTRUCTION PROGRAM OF BPLC}

Broadband Power Line Carrier (BPLC) programs requires the cable built to the various distribution sites, EPON technology is used for the remote access of information transmission, BPLC is used for transmitting in local channels, which broadband centralized equipments are configured in the power distribution stations, BPLC terminals are configured on meter boxes in each floor.

F. The electricity consumption data collection based on BPLC

The networking of electricity consumption data collection based on BPLC is shown Figure 4 


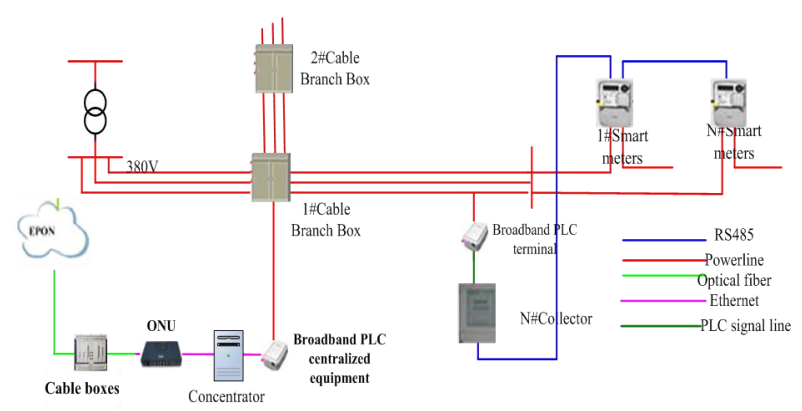

Fig.4 The electricity consumption data collection based on BPLC

The installation location of related equipment is as follows: a comprehensive electricity consumption information collection box is placing next to community's distribution transformers, for installing ONU, power outlet, splice boxes, concentrators and BPLC centralized device, the device power is taken from the total gate switch. Collecting device is installed in the meter box each corridor, the total power is taken from the meter box and with separate air breaker. Collecting device coupled signals to the power line through coupling magnetic, to achieve communication with the concentrator, and concentrators are connected to ONU via a network cable, ultimately connected with the main station.

\section{G. The intelligent electricity consumption service system based on BPLC}

The communities had been built a flexible interactive intelligent electricity consumption system, for the data communication of home users, the signal can be converted by BPLC device into a power line carrier signal, after extracting the signal through the coupler before it reaches the meter, BPLC centralized device converts the signal into Ethernet signal accessing the ONU, this signal is converted by ONU into an optical signal into the EPON network, while providing for the family of intelligent interactive terminal user management and support. Fig. 5 shows the logic of intelligent electricity consumption based on BPLC

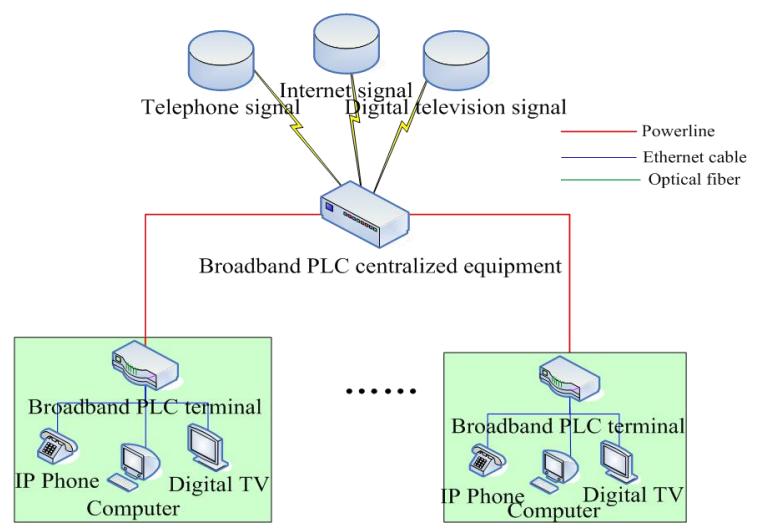

Fig. 5 The logic of intelligent electricity consumption based on BPLC

Fig. 6 shows the networking solutions of intelligent electricity consumption service system based on BPLC. 


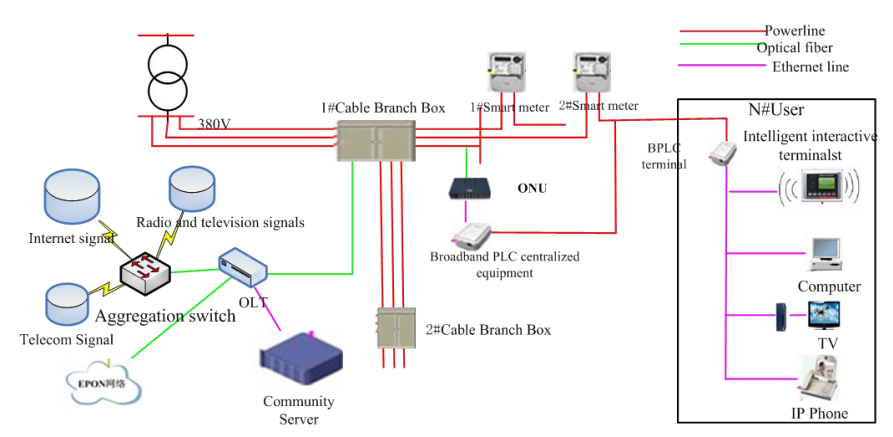

Fig.6 The networking solutions of intelligent electricity consumption service system based on BPLC

There are several options for network communication within the user households, besides Ethernet lines noted in Figure 6, can be power line carrier communication, can also be wireless communications such as ZigBee and WiFi.

\section{CONCLUSION}

This paper presents two modes network of AMI based on the characteristics of intelligent grid demonstration community in Guangxi province. Detailed speaking, the PFTTH mode which support $10 \mathrm{~km}$ and $20 \mathrm{~km}$ maximum transmission distance applies to the communities which power optical fiber communication facilities have been or will be laid from the substation to $10 \mathrm{kV}$ distribution transformers, such as community B. The BPLC mode which support 300 meters applies to the communities which optical fiber cannot be laid, such as community A. This result provides the theoretical foundation for the construction and promotion of the intelligent grid demonstration community project in China.

\section{ACKNOWLEDGMENT}

The authors thank for the Key Science \& Technology Project of China Southern Power Grid (WYKJ00000020) and the National Natural Science Foundation of China (51377119).

\section{REFERENCES}

[1] WANG Jing. A Survey on Power System Bad Data Detection and Identification [J]. Power \& Energy, 2015 (6): 813-817.

[2] LIU Li, ZHAI Denghui, JIANG Xinli. Current situation and development of the methods on bad-data detection and identification of power system [J]. Power System Protection and Control, 2010, 38(5):143-147.

[3] JIANG Delong, WANG Kewen, WANG Xiangdong. Clustering method of fuzzy equivalence matrix to bad-data detection and identification [J]. Power System Protection and Control, 2012, 39(21): 1-6.

[4] GUO Kunya, XIONG Xiong, JIN Peng. Electricity characteristic recognition study based on fuzzy clustering - quantum particle swarm algorithm [J]. Electric Power Construction, 2015, 36(8): 84-88.

[5] LIU Huizhou, ZHOU Kaile, HU Xiaojian. Bad Data Identification and Correction Based on Load Clustering by FCM Algorithm [J]. Electric Power, 2013, 46(10): 29-34.

[6] XIAO Mansheng, YANG Dilan, ZHANG Juwu. Research of weighting exponent of fuzzy Cmeans algorithm based on fuzzy relevance [J]. 2010, 30(12): 3388-3390.

[7] CHEN Xia, Fang Fang, Hu Zhanli. Fuzzy Clustering Methods [J]. Life Science Instruments, 2013(6):33-37. 
[8] DING Hongen, GAO Zonghe, SU Dawei. Solution to Bad Data Problem of Phase Angle Reference Bus for State Estimation with Hybrid Measurement [J]. Automation of Electric Power Systems, 2014, 38(9): 132-136.

[9] LIN Jikeng, LIU Lu, ZHANG Wenbo. Load Modeling and Parameter Identification Based on Random Fuzziness Clustering [J]. Automation of Electric Power Systems, 2013, 37(14): 50-58.

Li ting ( 1983- ) , female, lecture, the main research on electric power market, power system analysis and building automation. Her Email:174436467@qq.com

Zhang Shiyu ( 1986- ) , male, the Ph.D. student in Tianjin University. His research interesting in advanced metering infrastructure, distribution network planning, and smart gird.

Kong Xiangyu (1978- ), male, the communication author. His research interests are in smart grid, new energy and power system analysis, transient stability, and control. His Email: kongxy06@163.com. 